\title{
Experimental implementation of a smart battery charger for electric vehicles charging station
}

\author{
Abdelilah Hassoune ${ }^{1}$, Mohamed Khafallah², Abdelouahed Mesbahi ${ }^{3}$, Ayoub Nouaiti ${ }^{4}$, Tarik Bouragba ${ }^{5}$ \\ ${ }^{1,2,3,4}$ Laboratory of Energy and Electrical Systems, ENSEM, Hassan II University of Casablanca, Morocco \\ ${ }^{1,5}$ EIGSI Casablanca, Morocco
}

\begin{tabular}{l} 
Article Info \\
\hline Article history: \\
Received Dec 5, 2019 \\
Revised Apr 26, 2020 \\
Accepted May 18, 2020 \\
\hline Keywords: \\
Charging station \\
Closed-loop current control \\
DC/DC buck converter \\
DSP \\
Electric vehicles \\
Li-ion battery
\end{tabular}

\section{Article history:}

Received Dec 5, 2019

Revised Apr 26, 2020

Accepted May 18, 2020

\section{Keywords: \\ DC/DC buck converter \\ Electric vehicles \\ Li-ion battery}

\begin{abstract}
In this paper, an implementation of a DC/DC buck converter for electric vehicles charging station and a DSP based closed-loop digital controller design are presented and analyzed. The aim of this work is to achieve an improved control strategy for a Li-ion battery charger implemented on a Real-time test platform. The test platform consists of a popular power pole board (MPCA75136) dedicated to studying the DC/DC converters, and a DSP development kit (TMS320F28379D) that is used to drive the DC/DC buck converter. The control strategy is based on a digital control system containing the closed-loop current controller followed by a pulse width modulation block, and on a real time state of charge estimation technique for a Li-ion battery. However, the overall control design is modeled on Simulink via block diagrams, and automatically generated code that is targeted into the DSP processor. Simulation and experimental results have shown the effectiveness of the proposed test bench and its external digital control strategy via a charging scenario for electric vehicles batteries.
\end{abstract}

This is an open access article under the CC BY-SA license.

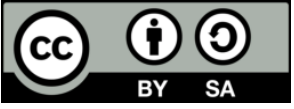

Corresponding Author:

Abdelilah Hassoune

ENSEM, Hassan II University of Casablanca

7 km El Jadida Road, 8118, Oasis, Casablanca, Morocco

EIGSI Casablanca. 282, l'Oasis Road, 20410, Casablanca, Morocco

Email: a.hassoune@ieee.org

\section{INTRODUCTION}

The global environmental change research has encouraged the use of more efficient and energy optimization technologies in many sectors of daily life. Major energy consumptions are recently noticed in the transportation field, especially in the automobile industry [1]. Therefore, the need of more effective use of electric vehicles charging station (EVCS) is become increasingly competitive due to the improvement of the embedded information systems, and of the operation modes for electric vehicle (EV) battery charger in smart grids $[2,3]$. Furthermore, the topologies of energy conversion devices had drawn much attention due to its various benefits, as the improved accuracy, stability and decreasing the energy losses during charging operations. Several such topologies of energy converters have been discussed and compared in [4-6]. The DC/DC buck converter offers a high energy efficiency and a large scale of output current compared to the other types of chargers, and it could possibly be used to interface the DC bus of the EVCS to the EV battery [7]. Each rated power provided by the battery chargers represents a specific charging mode; mode-1: slow charging (up to $3 \mathrm{~kW}$ ), mode-2: fast charging (providing power from $7 \mathrm{~kW}$ to $22 \mathrm{~kW}$ ), mode-3: rapid charging (rapid AC chargers are rated at $43 \mathrm{~kW}$, while most Rapid DC terminals are at least 50kW) [8-10].

Numerous control strategies for charging EV batteries have been reported in the literature [11]. The constant current-constant voltage $(\mathrm{CC}-\mathrm{CV})$ is by far the most familiar one, it consists of a constant current 
charging protocol where the battery voltage increases up to a threshold level, followed by a constant voltage control mode hold until the current falls down to a low value. Thus, the simplicity of implementation of the $\mathrm{CC}-\mathrm{CV}$ control has made it the most used charging protocol in the battery management system (BMS) applications [12]. This kind of protocols can shorten the charging time, with less damage of battery cycle life. Other protocols as in [13] have been proved to reduce charging times, and increased energy efficiency.

The MPCA75136 power pole board (PPB) used in this paper is a platform in which control algorithms can be rapidly deployed and tested [14]. The control strategy of the PPB is implemented on a TMS320F28379D DSP, it consists of a closed-loop current control system followed by a digital pulse width modulation (PWM) block and a decision algorithm of duty cycle. One of the main aims of this work is to provide a smart embedded platform that can be used to test various digital controls on power electronic converters without going into the details of $\mathrm{C}$ programming of microcontrollers, or of converter schematics. In order to control the injected power flow into the connected battery, the authors in $[15,16]$ proposed a SOC estimation technique for Li-Ion battery based on a DSP hardware that can be used as a real-time tool for the embedded system platforms. The software tools required to set such control strategies are Matlab/Simulink, and Code Composer [17-19]. The works in [20] are closely related to the present work, it describes a power electronics laboratory that consists of Simulink and TI F28035 processor in order to control DC/DC converters.

This paper is structured as follows: Section 1 introduces the background of the used approach. The real-time test platform of the EVCS smart charger operated by a TMS320F28379D DSP is described in Section 2. The closed-loop current digital control is detailed in Section 3. Design and simulation results in Simulink are presented in Section 4. Experimental results of a fast and a rapid charging mode are performed and analyzed in Section 5. Conclusions are provided in Section 6.

\section{DESCRIPTION OF THE PROPOSED PLATFORM}

Figure 1 depicts the complete scheme of the proposed real-time test platform; it consists of an EV Li-ion battery tied to a multi-source power system of the charging station via a DC/DC buck converter. The EV battery charger is controlled by a hybrid control strategy composed by a constant current mode supported by a threshold voltage mode. The digital control system (DCS) is driven by a control algorithm based on user control panel (UCP) data, so that the DCS can generate the required settings for the charger power switch.

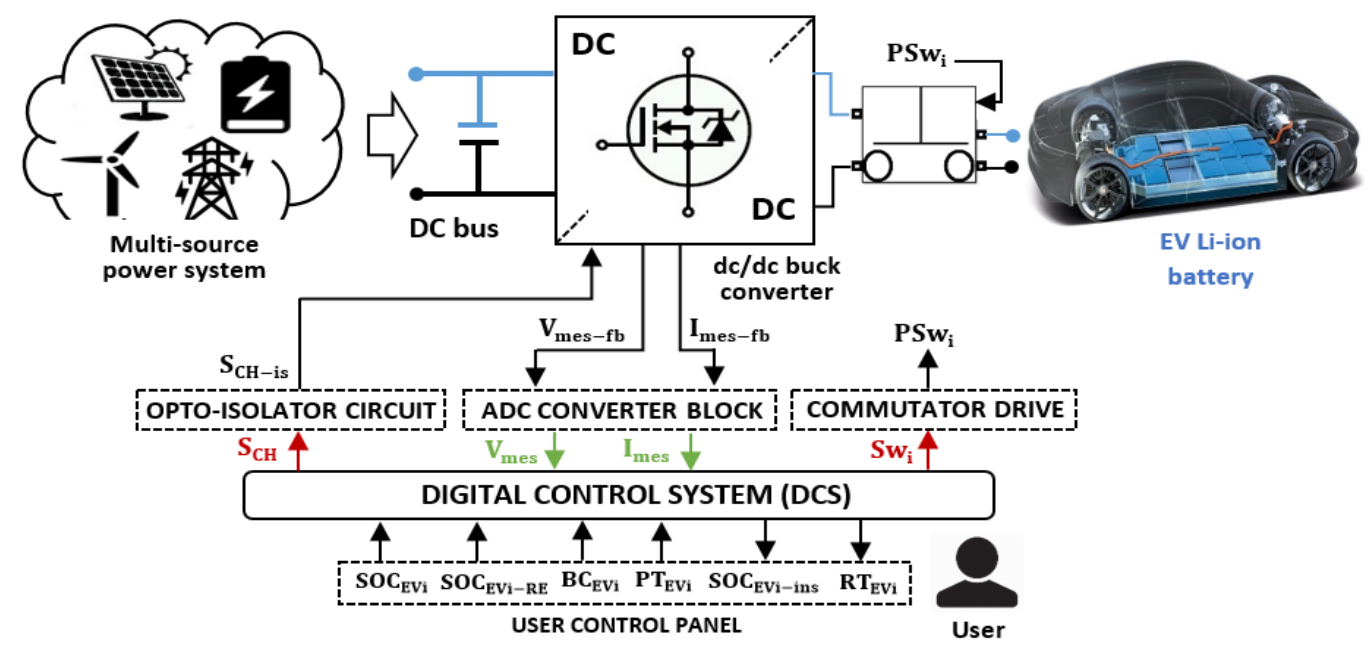

Figure 1. Block diagram of the proposed Real-time test platform of the EVCS charger

\section{CLOSED-LOOP DIGITAL CONTROL STRATEGY}

The EV battery charger is a multi-block system on which measurement sensors can be implemented in order to feed the DCS with the charging operation data, as shown in Figure 2. The internal block diagram of the proposed DCS is illustrated in Figure 3, it consists of several stages aimed to fulfill the desired charging modes of each EV battery via UCP data and a real time processing of the charging current and voltage. 


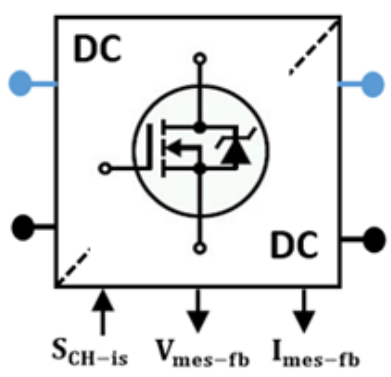

(a)

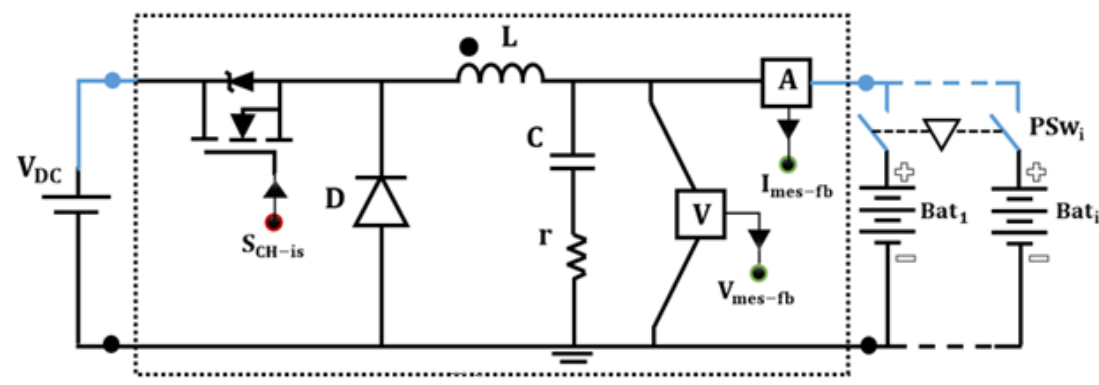

(b)

Figure 2. DC/DC buck converter on the power pole circuit board (a) external view, (b) internal view

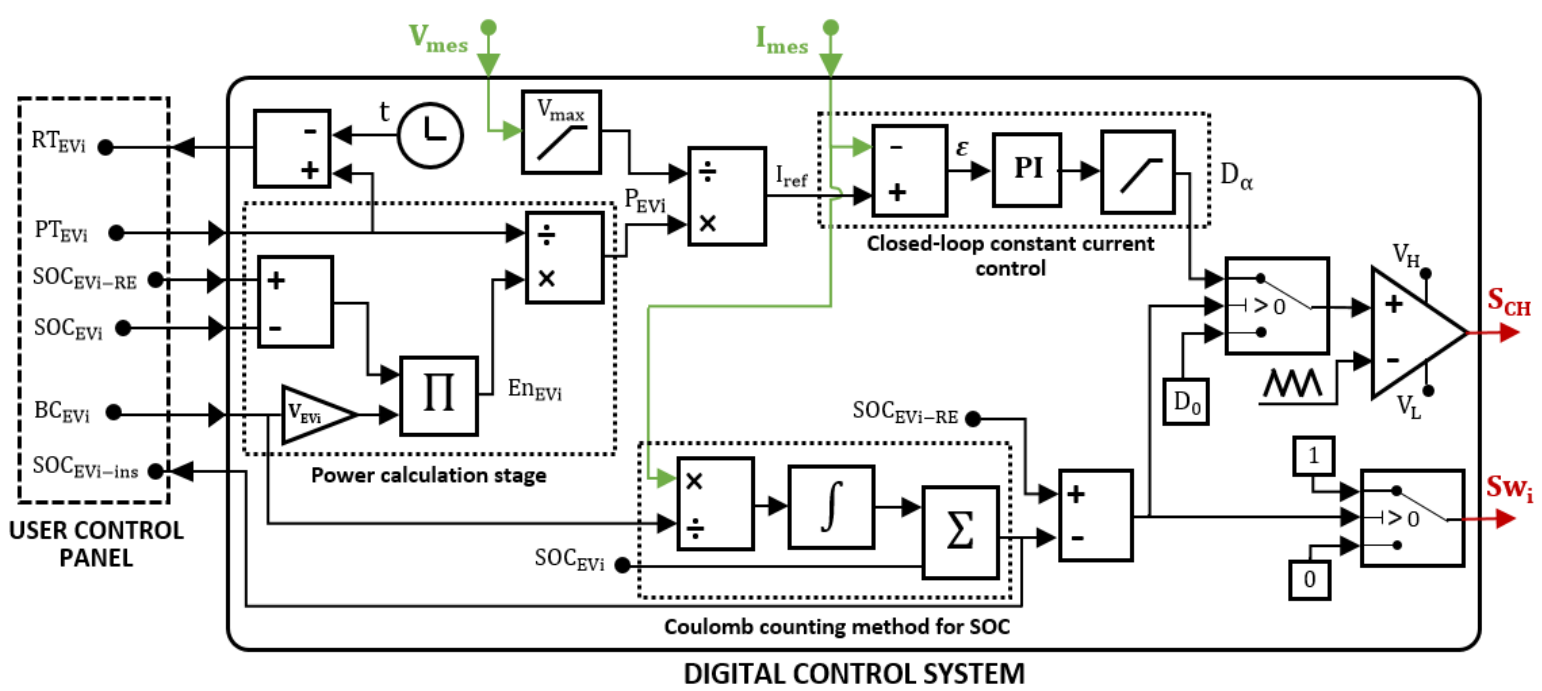

Figure 3. Internal block diagram of the proposed DCS

Compared to conventional technologies of batteries, Li-ion battery charges faster, and has a higher power density [21]. It is therefore proposed to use the Li-ion battery in the present work in order to emulate the EV storage system behaviour. It can be modeled through an electrical-analogue model [22] as shown in Figure 4. The battery terminal voltage is a reflection of the battery open-circuit voltage $\left(\mathrm{E}_{0}\right)$, internal resistance $\left(\mathrm{R}_{0}\right)$, and transient effects caused by charging or discharging current. The adopted model is dynamical, in which several components approximate different features of the dynamic response of a real battery. The $\mathrm{N}$ sets of RC networks are used to represent the model with continuous state variables.

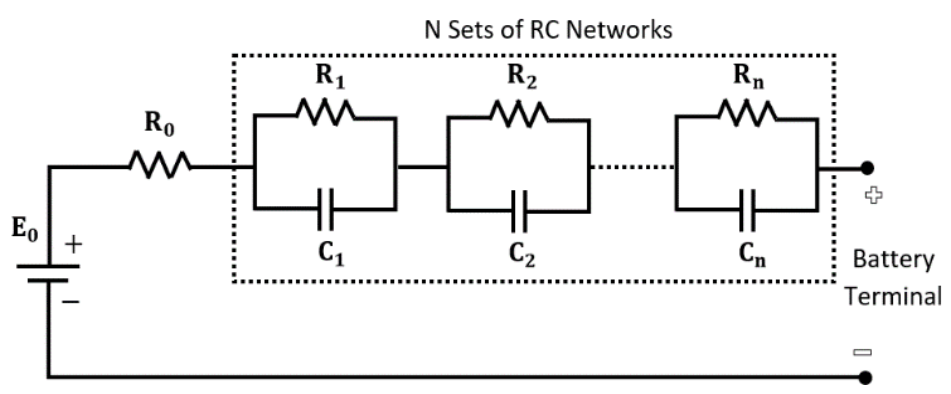

Figure 4. The electrical-analogue Li-ion battery model

The Li-ion battery impedance can be written as in (1). In what follows, a two RC network of the battery model is selected to depict the charging operation of an ith EV battery.

Experimental implementation of a smart battery charger for electric vehicles ... (Abdelilah Hassoune) 


$$
\mathrm{Z}_{\mathrm{B}}(s)=\mathrm{R}_{0}+\frac{\mathrm{R}_{1}}{1+\mathrm{R}_{1} \mathrm{C}_{1} \mathrm{~s}}+\frac{\mathrm{R}_{2}}{1+\mathrm{R}_{2} \mathrm{C}_{2} \mathrm{~s}}+\cdots \frac{\mathrm{R}_{\mathrm{n}}}{1+\mathrm{R}_{\mathrm{n}} \mathrm{C}_{\mathrm{n}} \mathrm{s}}
$$

\subsection{Power calculation stage}

In compliance with the applied power demand from electric vehicles batteries, the DC bus of the charging station must provide the required energy within the plugging allocated time. In the framework of which UCP can provide real time monitoring of the charging sequence, the remaining time (RTEVi) of the charging operation can be calculated from the plugging time (PTEVi) as:

$$
\mathrm{RT}_{\mathrm{EVi}}=t-\mathrm{PT}_{\mathrm{EVi}}
$$

based on the charging scenario considerations, the DCS of the EVCS would calculate the needed energy and then would generate a reference value of the charging power (PEVi), its expression is given in (3).

$$
\mathrm{P}_{\mathrm{EVi}}=\frac{\left(\mathrm{SOC}_{\mathrm{EVi}-\mathrm{RE}}-\mathrm{SOC}_{\mathrm{EVi}}\right) \times \mathrm{BC}_{\mathrm{EVi}}}{\mathrm{PT}_{\mathrm{EVi}}}
$$

Where BCEVi is the battery capacity of an ith EV. The reference current (Iref) of the closed-loop control is generated from this stage as expressed in (4). It is primordial to limit the charging voltage within a maximum level in order to avoid critical overloading issues, such as a danger of overheating.

$$
\mathrm{I}_{\mathrm{ref}}=\frac{\mathrm{P}_{\mathrm{EVi}}}{\mathrm{V}_{\mathrm{mes}}}
$$

\subsection{Constant-current charging protocol}

The improved charging protocol aims to set a constant current control on the battery charger, it is also intended to control the voltage for not exceeding the overloading level of the connected battery. The block diagram of the closed-loop control of the buck converter is depicted in Figure 5.

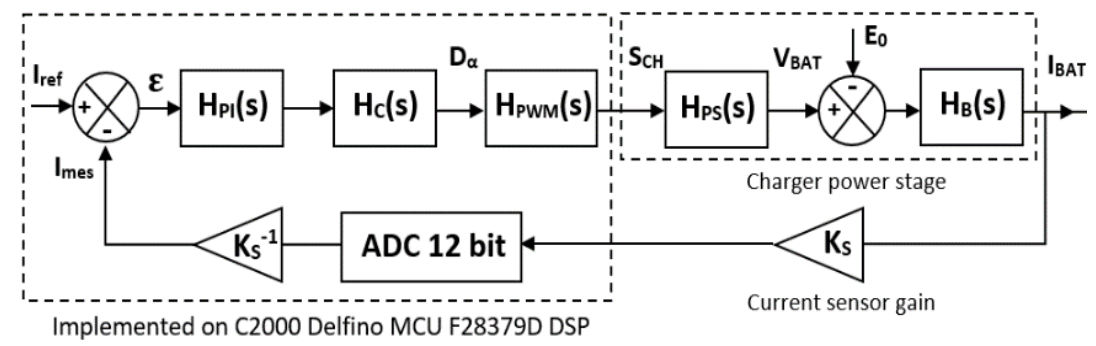

Figure 5. The improved closed-loop constant current control

The portioned block is implemented digitally on the used development kit i.e., TMS320F28379D DSP. The reference input $I_{\text {ref }}$ (which specifies the desired charging current) is initialized via the power calculation block. The error signal is driven by PI controller, that is expressed as in (5).

$$
\mathrm{H}_{\mathrm{PI}}(s)=\mathrm{K}_{\mathrm{p}}+\frac{\mathrm{K}_{\mathrm{i}}}{\mathrm{s}}=\mathrm{K}_{\mathrm{P}} \times\left(1+\frac{1}{\mathrm{~T}_{\mathrm{i}} s}\right)
$$

Where, $\mathrm{K}_{\mathrm{p}}$ is the gain of proportional action, $\mathrm{K}_{\mathrm{i}}$ is the gain of integral action. $\mathrm{H}_{\mathrm{C}}$ (s) described in (6) represents the delay due to the calculation times and the execution of the DSP [23].

$$
\mathrm{H}_{\mathrm{C}}(s)=\frac{1}{1+1.5 \mathrm{~s} \mathrm{~T}_{\mathrm{S}}}
$$


The pulse width modulator is programmed to produce PWM signals at a switching frequency of $25 \mathrm{kHz}$. The system clock on the TMS320F28379D DSP has a frequency of $200 \mathrm{MHz}$ [24]. In order to provide a switching frequency of $25 \mathrm{kHz}$, the system clock must be divided down by a factor of 8000 . Therefore, the control signal $\mathrm{D}_{\alpha}$ that determines the duty cycle of $\mathrm{S}_{\mathrm{CH}}$ must be in the range 0-7999. The ePWM block can produce 8000 equally space duty cycles over the range $0<\mathrm{S}_{\mathrm{CH}}<1$. The equation that expresses the regulated signal and the duty cycle is presented in (7).

$$
\mathrm{H}_{\mathrm{PWM}}(s)=\frac{\delta \mathrm{S}_{\mathrm{CH}}}{\delta \mathrm{D}_{\alpha}}=\frac{1}{8000}
$$

The transfer function of the buck converter power stage is well known [25], it is expressed as:

$$
\mathrm{H}_{\mathrm{PS}}(s)=\frac{\mathrm{V}_{\mathrm{DC}} r}{L} \frac{\left(s+\frac{1}{r C}\right)}{s^{2}\left(1+\frac{r}{\mathrm{Z}_{\mathrm{B}}(s)}\right)+s\left(\frac{r}{L}+\frac{1}{\mathrm{Z}_{\mathrm{B}}(s) C}\right)+\frac{1}{L C}}
$$

Given the adopted model of the Li-ion battery, the conductance function of two sets of RC networks can be synthesized from (1) as follows:

$$
\mathrm{H}_{\mathrm{B}}(s)=\frac{1}{\mathrm{R}_{0}+\frac{\mathrm{R}_{1}}{1+\mathrm{R}_{1} \mathrm{C}_{1} \mathrm{~s}}+\frac{\mathrm{R}_{2}}{1+\mathrm{R}_{2} \mathrm{C}_{2} \mathrm{~s}}}
$$

\subsection{Coulomb counting method}

The coulomb-counting algorithms are often used in the battery management systems, they describe the SOC as the ratio of available capacity to the nominal one [26]. The available capacity in a connected battery operated under charging operation mode can be calculated by measuring its charging current flow and integrating it over the time interval. The used equation to calculate the instantaneous SOC is given as:

$$
\operatorname{SOC}_{\mathrm{EVi} \text {-ins }}(s)=\mathrm{SOC}_{\mathrm{EVi}}+\frac{\mathrm{I}_{\mathrm{mes}} \times \mathrm{K}}{\mathrm{B} C_{\mathrm{EVi}} \times \mathrm{s}}
$$

Where, $\mathrm{SOC}_{\mathrm{EV} \text { i-ins }}$ is the $\mathrm{SOC}$ of an $\mathrm{EV}$ battery in real-time processing, $\mathrm{SOC}_{\mathrm{EVi}}$ represents the initial $\mathrm{SOC}, \mathrm{I}_{\text {mes }}$ represents the charging current, $\mathrm{BC}_{\mathrm{EVi}}$ is the nominal capacity of the battery, and $\mathrm{K}$ is the input gain of the integrator.

\section{SIMULATION RESULTS}

In order to check the validity of the proposed Real-time test platform, a closed-loop current digital controller design is carried out in MATLAB/Simulink. The modeled block diagram is depicted in Figure 6, it consists of a low power prototype of a real-time test platform of EV battery charger.

The charging power is measured in the scale of watts which emulates the high-power charging scenarios. Thus, a DC bus voltage $\mathrm{V}_{\mathrm{DC}}$ is stabilized at $30 \mathrm{~V}$, within a maximum power of $90 \mathrm{~W}$, the load is represented by a Li-ion battery of $12 \mathrm{~V} / 4 \mathrm{Ah}$. The specification of the proposed DC/DC buck converter used in simulation is given in Table 1 .

The simulation features are based, on the one hand, on testing the proposed closed-loop control via constant current method improved by threshold voltage control, on the other hand, on a real-time monitoring of the charging process using the coulomb counting algorithm of estimating the SOC. The rapid and the fast charging modes are emulated by a charging scenario of two EV batteries connected in two different time intervals, Table 2 shows the used scenario.

As can be seen from the Figure 6, the two charging modes of the proposed scenario are implemented through power switches controlled by a decision algorithm. However, Figure 7 depicts the simulation results of the charging current and the injected power into two Li-ion batteries. Based on the scenario data in Table 2 and the expression of eq. (2), the power required by each vehicle battery is $57.6 \mathrm{~W}$ for the one that is rapid (above $50 \mathrm{~W}$ ), and $19.2 \mathrm{~W}$ for the other that is fast ( $7 \mathrm{~W}$ to $22 \mathrm{~W}$ ). 


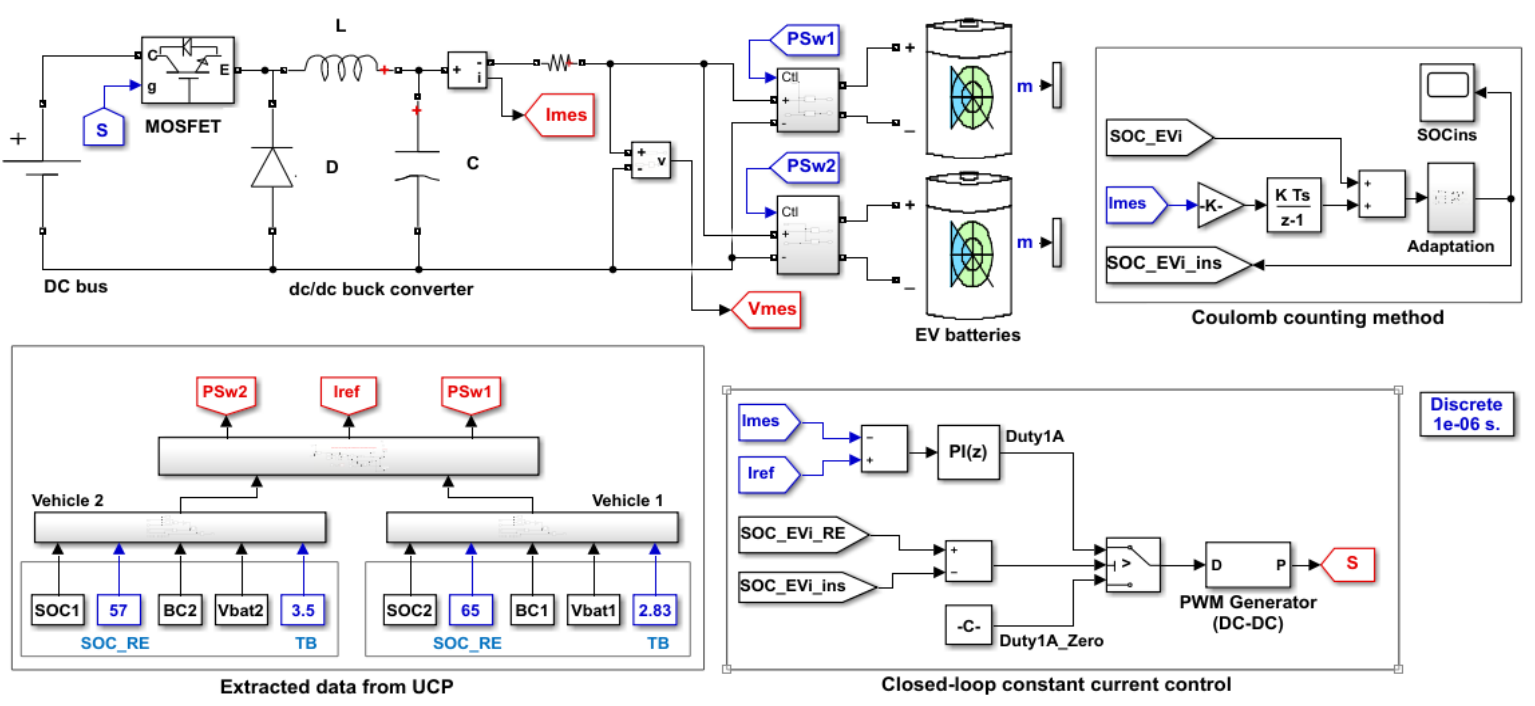

Figure 6. Block diagram of the proposed Real-time test platform modeled on Simulink

Table 1. Parameters of the simulation setup

\begin{tabular}{ll}
\hline Parametes & Setup value \\
\hline Input voltage, $\mathrm{V}_{\mathrm{DC}}$ & $30 \mathrm{~V}$ \\
Output voltage, $\mathrm{V}_{\mathrm{BAT}}$ & $12 \mathrm{~V}$ \\
Buck inductor, $\mathrm{L}$ & $100 \mu \mathrm{H}$ \\
Buck capacitor, C & $690 \mu \mathrm{F}$ \\
ESR of capacitor, $\mathrm{r}$ & $0.128 \Omega$ \\
Switching frequency, Fs & $25 \mathrm{kHz}$ \\
\hline
\end{tabular}

Table 2. Charging scenario of two electric vehicles batteries

\begin{tabular}{llllll}
\hline BAT & $\begin{array}{l}\mathrm{PT}_{\mathrm{EVi}} \\
(\mathrm{min})\end{array}$ & $\begin{array}{l}\mathrm{SOC}_{\mathrm{EVi}} \\
(\%)\end{array}$ & $\begin{array}{l}\mathrm{SOC}_{\mathrm{EV} \text {-RE }} \\
(\%)\end{array}$ & $\begin{array}{l}\text { Charging } \\
\text { mode }\end{array}$ & $\begin{array}{l}\mathrm{En}_{\mathrm{EVi}} \\
(\mathrm{Wh})\end{array}$ \\
\hline 1 & 2.83 & 61 & 65 & Rapid & 2.66 \\
2 & 3.5 & 55 & 57 & Fast & 1.12 \\
\hline
\end{tabular}

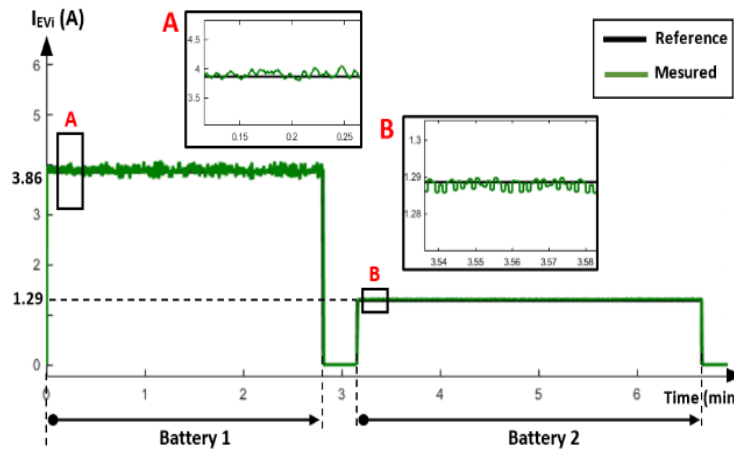

(a)

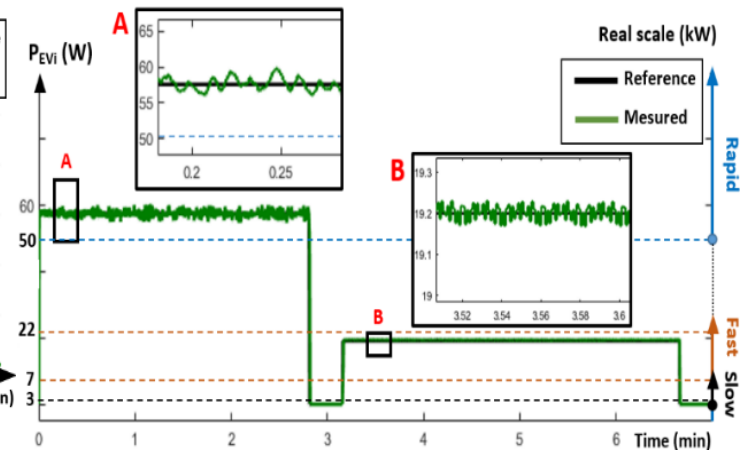

(b)

Figure 7. Simulation results of rapid and fast charging modes (a) current waveform (b) power waveform

In the charging current waveform, the system reacted efficiently to the quick change in reference values. At $\mathrm{t}=0 \mathrm{~min}$, the first battery was connected and then charged with an effective value of current rate of $3.86 \mathrm{~A}$, after $2.83 \mathrm{~min}$ of plugging event, its SOC had reached the required level of $65 \%$. The second scenario was started at $\mathrm{t}=3.15 \mathrm{~min}$, the real-time processing of data set an update of the reference current at $1.29 \mathrm{~A}$. There is a quick tracking of the reference current, the same reaction is noticed in the charging power curve, the measured power is around its reference value set by the DCS. In order to facilitate the analysis results and to get effective synthesis, a waveform of the instantaneous SOC of both batteries is shown in Figure 8 . 


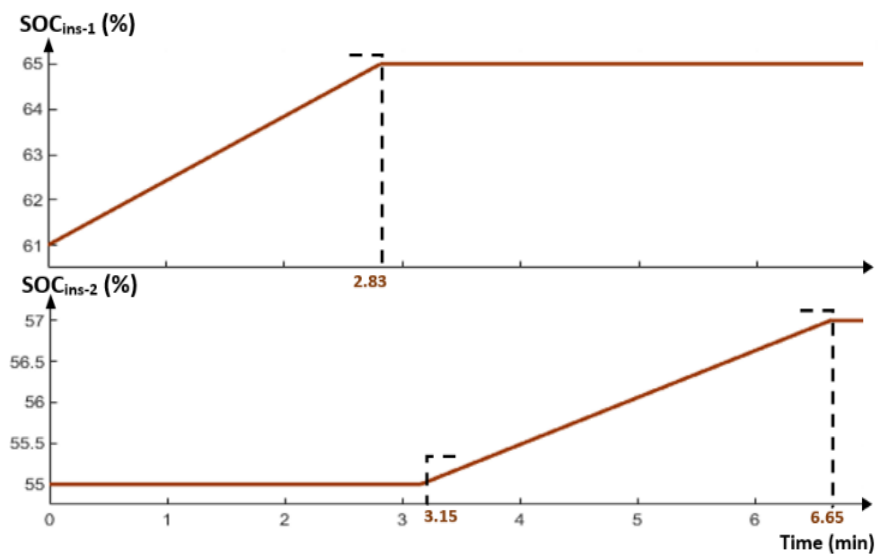

Figure 8. Simulation results of the SOC waveform based on Coulomb counting algorithm

A gradual change in SOC is observed in the two the charging modes. Therefore, the obtained results prove the convergence of the measurement values towards the values set by UCP.

\section{RESULTS AND DISCUSSION}

The proposed control strategy is tested on an experimental test bench assembled and operated at the power electronics laboratory as illustrated on Figure 9. The DC bus power of the MPCA75136 power circuit is provided by a DC power supply. PWM signals to control the MOSFET are supplied from an external source, which in this case is the TMS320F28379D DSP. The parameters of Table 1 are used in this setup, to complete the demonstration, a Li-ion battery is integrated to perform the $12 \mathrm{~V} / 4 \mathrm{Ah}$ load.

The designed Simulink model used to build the program code for TMS320F28379D DSP is presented in Figure 10. The ADC block samples the inductor current and the output voltage sequentially, these signals are scaled to get real-time values of the power stage. As described in Sec. 2, the range of $D_{\alpha}$ is from 0 to 7999, the PI saturation block adjusts the $D_{\alpha}$ in the range of 160-7600, that would avoid duty ratio close to $0 \%$ or $100 \%$. The schematic of the closed-loop control and of the PWM block is driven by a decision algorithm.

The decision algorithm stage would avoid the charger from exceeding the desired SOC of each connected EV battery. However, the system response waveform for step-down the reference current from 3.86 to $1.29 \mathrm{~A}$ is shown in Figure 11. The used control result suffers from inductor current oscillations but reaches the required reference value within a short delay.

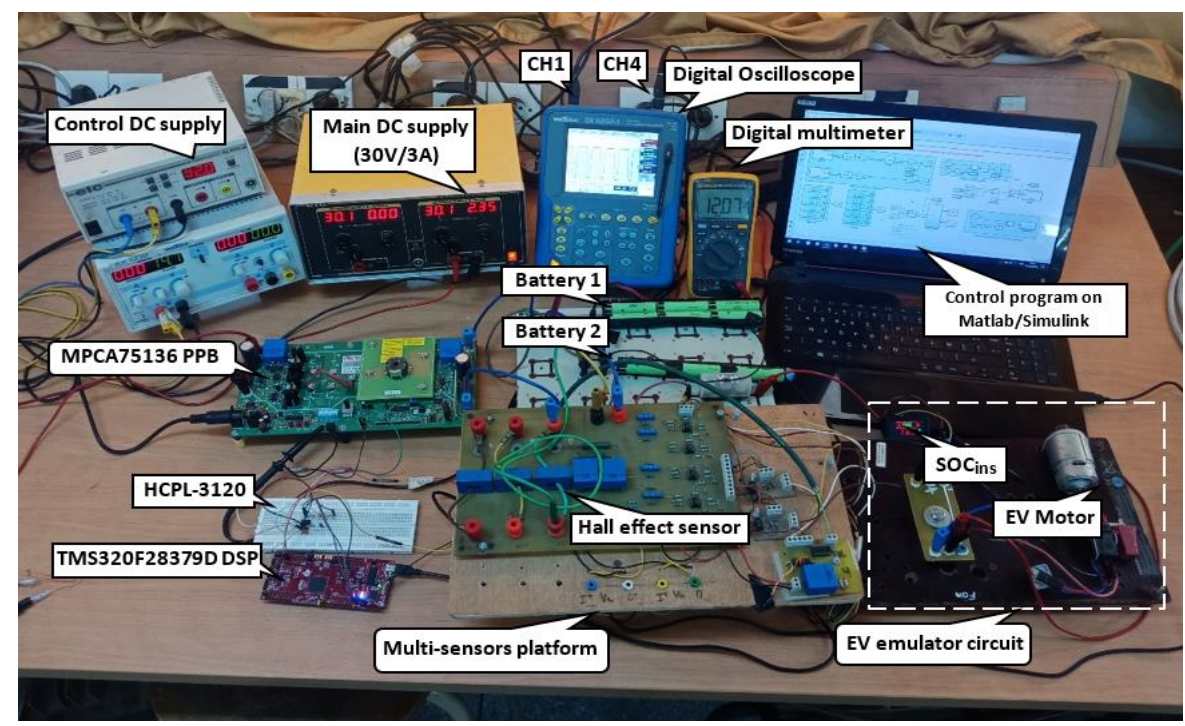

Figure 9. Experimental setup of the proposed Real-time test platform 


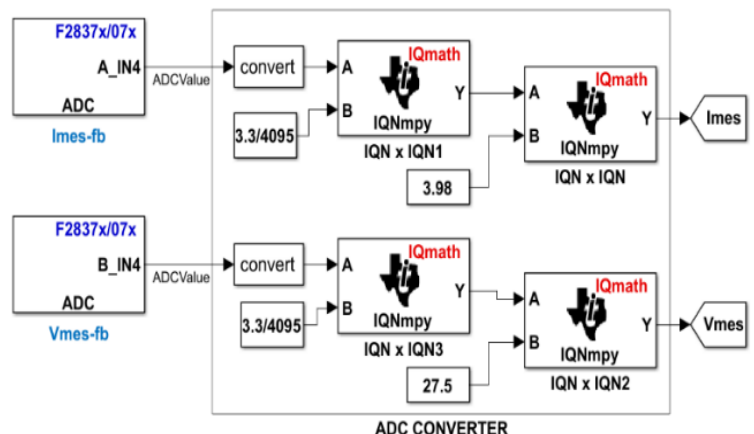

(a)

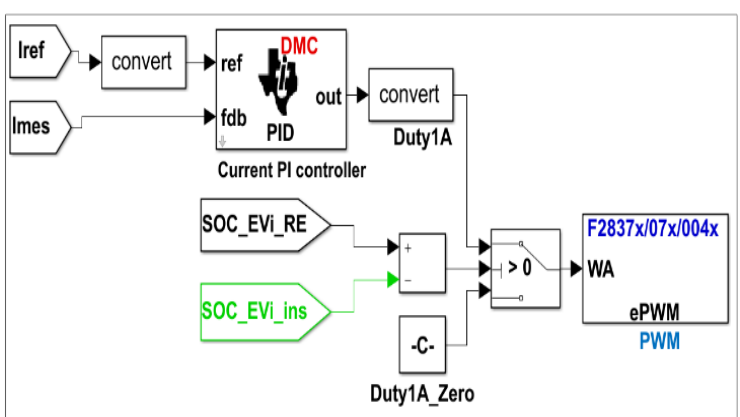

(b)

Figure 10. The designed Simulink model (a) ADC converter block (b) PWM block

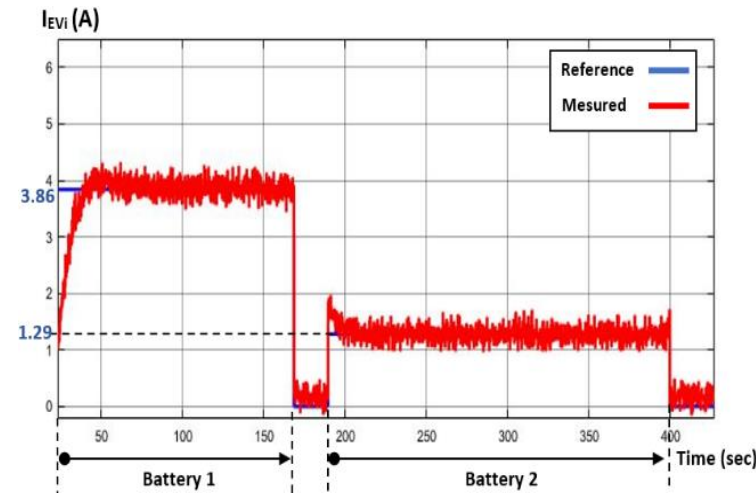

(a)

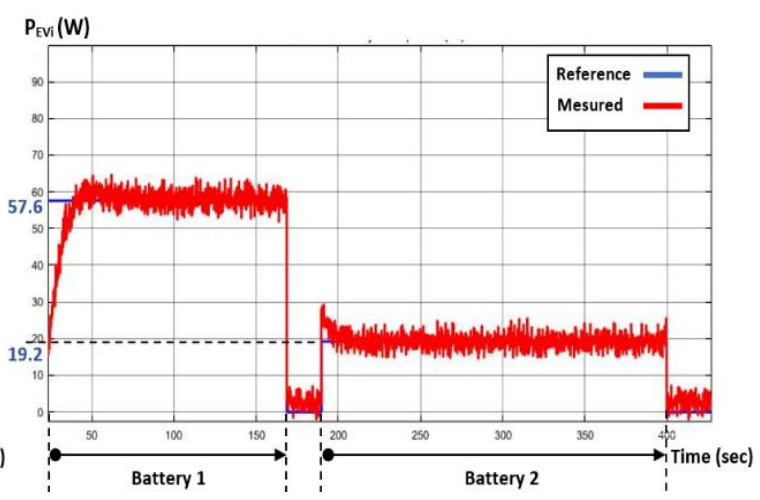

(b)

Figure 11. Experimental results of the proposed charging scenario (a) current waveform (b) power waveform

The second charging sequence that was started at $\mathrm{t}=190 \mathrm{sec}$ has a charging current of an effective value equal to $1.29 \mathrm{~A}$, and a reduced ripple rate in the range of $10-15 \%$. Therefore, the out of range impact of current ripple causes a battery performance degradation as reported in [27]. The reference current set to be rapidly changed, the steady state behaviour of the system is thus as expected. The closed-loop control system maintains the output power at each reference value even if the load is altered between two Li-ion batteries in different time intervals i.e., $\mathrm{t}=170-190 \mathrm{sec}$ and after $\mathrm{t}=400 \mathrm{sec}$. Meanwhile, the DCS monitors both the current and the voltage across the battery so that it will never exceed an overload voltage and the charging will take place during the time interval allocated by each EV user. However, Figure 12 shows the experimental measurement of the SOC in real time processing.

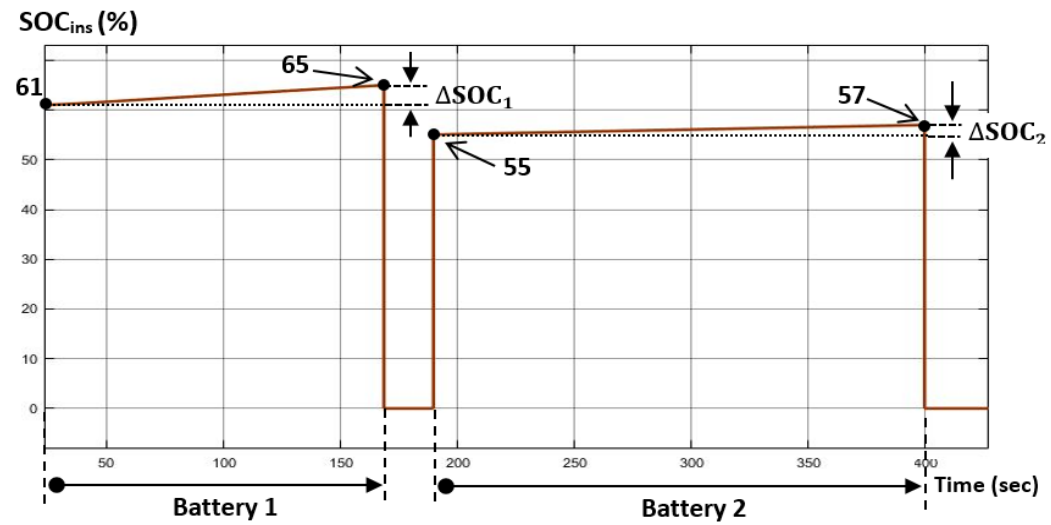

Figure 12. Experimental results of the SOC waveform based on Coulomb Counting algorithm 
The first battery SOC reached the required rate within $t=170 \mathrm{sec}$, which is the same plugging time allocated by the corresponding EV user $(2.83 \mathrm{~min})$. The fast charging mode is emulated in the second sequence where the battery is charged within $t=210 \mathrm{sec}$, means $3.5 \mathrm{~min}$ of plugging the battery into the EVCS terminal. The proposed charging scenario had verified the exposed control strategy which remains valid for the charging scenarios that can last a long duration time and require high charging power demand.

\section{CONCLUSION}

In this paper, a real-time test platform is presented in full detail in which an improved closed-loop constant current digital control is implemented on a Li-ion battery charger of EVCS. In order to develop the proposed control algorithm, a PI control with anti-windup correction and a column counting method of SOC were performed via a charging scenario emulating two charging modes i.e., fast and rapid. A steady state analysis of the experimental results highlights that both the power ripples and the charging current ripples were found to be decreased within the tolerable range. Apart from the proposed test platform, it is also important to analyze the economic and the reliability aspects of the DC bus power system based on hybrid energy sources, which can also be treated as the future scope of this work. The power pole circuit, the TI development kit, and Simulink combine to set effective real-time test platforms for evaluating control algorithms based on digital PWM. This has important implications for the BMS control algorithms. Overall, the proposed platform can be used to deploy and experiment digital controllers for buck, boost, buck-boost, flyback, and forward converters in research laboratories.

\section{REFERENCES}

[1] A. Moro and L. Lonza, "Electricity carbon intensity in European Member States: Impacts on GHG emissions of electric vehicles," Transportation Research Part D: Transport and Environment, vol. 64, pp. 5-14, Oct. 2018.

[2] V. Monteiro, J. G. Pinto, and J. L. Afonso, "Improved vehicle-for-grid (iV4G) mode: Novel operation mode for EVs battery chargers in smart grids," International Journal of Electrical Power \& Energy Systems, vol. 110, pp. 579-587, Sep. 2019.

[3] A. Hassoune, M. Khafallah, A. Mesbahi, and T. Bouragba, "Power Management Strategies of Electric Vehicle Charging Station Based Grid Tied PV-Battery System," International Journal of Renewable Energy Research (IJRER), vol. 8, no. 2, pp. 851-860, Jun. 2018.

[4] H. Wang, A. Gaillard, and D. Hissel, "A review of DC/DC converter-based electrochemical impedance spectroscopy for fuel cell electric vehicles," Renewable Energy, vol. 141, pp. 124-138, Oct. 2019.

[5] M. Lakshmi and S. Hemamalini, "Coordinated control of MPPT and voltage regulation using single-stage high gain DC-DC converter in a grid-connected PV system," Electric Power Systems Research, vol. 169, pp. 65-73, Apr. 2019.

[6] K. Jyotheeswara Reddy and S. Natarajan, "Energy sources and multi-input DC-DC converters used in hybrid electric vehicle applications-A review," International Journal of Hydrogen Energy, vol. 43, no. 36, pp. 1738717408, Sep. 2018.

[7] A. Mendoza-Torres, N. Visairo, C. Nuñez, J. Armenta, E. Rodríguez, and I. Cervantes, "Switching rule for a bidirectional DC/DC converter in an electric vehicle," Control Engineering Practice, vol. 82, pp. 108-117, 2019.

[8] M. Amjad, A. Ahmad, M. H. Rehmani, and T. Umer, "A review of EVs charging: From the perspective of energy optimization, optimization approaches, and charging techniques," Transportation Research Part D: Transport and Environment, vol. 62, pp. 386-417, Jul. 2018.

[9] A, Tomaszewska, Z. Chu, X. Feng, et al, "'Lithium-ion battery fast charging: A review", eTransportation, vol. 1, pp. 1-6, Aug. 2019.

[10] A. Hassoune, M. Khafallah, A. Mesbahi, and T. Bouragba, "Improved Control Strategies of Electric Vehicles Charging Station based on Grid Tied PV/Battery System," International Journal of Advanced Computer Science and Applications, vol. 11, no. 3, 2020.

[11] J. López, S. I. Seleme, P. F. Donoso, L. M. F. Morais, P. C. Cortizo, and M. A. Severo, "Digital control strategy for a buck converter operating as a battery charger for stand-alone photovoltaic systems," Solar Energy, vol. 140, pp. 171-187, Dec. 2016.

[12] S. Soeprapto, R. N. Hasanah, and T. Taufik, "Battery management system on electric bike using Lithium-Ion 18650," International Journal of Power Electronics and Drive Systems (IJPEDS), vol. 10, no. 3, p. 1529, Sep. 2019.

[13] O. Ellabban, J. V. Mierlo, and P. Lataire, "A DSP-Based Dual Loop Digital Controller Design and Implementation of a High-Power Boost Converter for Hybrid Electric Vehicles Applications," Journal of Power Electronics, vol. 11, no. 2, pp. 113-119, Mar. 2011.

[14] C. P. Mathews and B. Y. Mitsui, "Closed-Loop Digital PWM Control using a Popular Power Electronics Platform," IFAC-PapersOnLine, vol. 48, no. 30, pp. 351-356, 2015.

[15] J. Luo, J. Peng, and H. He, "Lithium-ion battery SOC estimation study based on Cubature Kalman filter," Energy Procedia, vol. 158, pp. 3421-3426, Feb. 2019.

[16] Y. Liu, Y. Wang, and Z. Yan, “Accelerating PID controller development with rapid prototyping and model-based design," Pacific Science Review A: Natural Science and Engineering, vol. 17, no. 2, pp. 48-50, Jul. 2015.

Experimental implementation of a smart battery charger for electric vehicles ... (Abdelilah Hassoune) 
[17] Y. Shi, B.-H. Gwee, and J. Chang, "Asynchronous DSP for low-power energy-efficient embedded systems," Microprocessors and Microsystems, vol. 35, no. 3, pp. 318-328, May 2011.

[18] Kamal, T., Nadarajah, M., Hassan, S.Z., et al, "Optimal Scheduling of PHEVs in a PV based Charging Station," International Conference on Emerging Technologies, Islamabad, Pakistan, October 2016, pp. 1-6.

[19] A. Hassoune, M. Khafallah, A. Mesbahi, L. Benaaouinate, and T. Bouragba, "Control Strategies of a Smart Topology of EVs Charging Station Based Grid Tied RES-Battery," International Review of Electrical Engineering (IREE), vol. 13, no. 5, p. 385, Oct. 2018.

[20] S. Choi and M. Saeedifard, "An Educational Laboratory for Digital Control and Rapid Prototyping of Power Electronic Circuits," IEEE Transactions on Education, vol. 55, no. 2, pp. 263-270, May 2012.

[21] A.-I. Stroe, V. Knap, and D.-I. Stroe, "Comparison of lithium-ion battery performance at beginning-of-life and end-of-life,” Microelectronics Reliability, vol. 88-90, pp. 1251-1255, Sep. 2018.

[22] J. Li and M. S. Mazzola, "Accurate battery pack modeling for automotive applications," Journal of Power Sources, vol. 237, pp. 215-228, Sep. 2013.

[23] A. Nouaiti, A. Mesbahi, A. Saad, M. Khafallah, and M. Reddak, "Realization of a Single-Phase Multilevel Inverter for Grid-Connected Photovoltaic System”, Eng. Technol. Appl. Sci. Res., vol. 8, no. 5, pp. 3344-3349, Oct. 2018.

[24] S. B. Santra, K. Bhattacharya, T. R. Chudhury, and D. Chatterjee, "Generation of PWM Schemes for Power Electronic Converters," 2018 20th National Power Systems Conference (NPSC), Dec. 2018.

[25] N. Mohan, "Power Electronics: A First Course", Chapter 4. John Wiley and Sons, pp. 1-288, 2012.

[26] H.-S. Lee, B. Kang, W.-S. Kim, and S.-J. Yoon, "Reduction of input voltage/current ripples of boost half-bridge DC-DC converter for photovoltaic micro-inverter," Solar Energy, vol. 188, pp. 1084-1101, Aug. 2019.

[27] M. B. Lazreg, I. Baccouche, S. Jemmali, B. Manai, and M. Hamouda, "SoC Estimation of Li-Ion Battery Pack for Light Electric Vehicles using Enhanced Coulomb Counting Algorithm," 2019 10th International Renewable Energy Congress (IREC), Mar. 2019.

\section{BIOGRAPHIES OF AUTHORS}

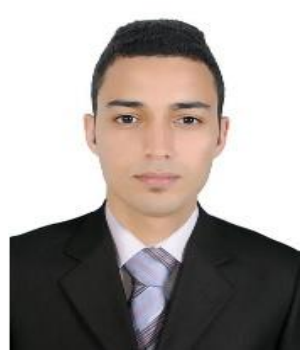

Abdelilah Hassoune was born in Settat, Morocco in 1993. He received the bachelor diploma in mathematical sciences in 2010, and the technical university degree in electrical engineering and computer science from the National High School of Technical Education, Mohammedia, Morocco, in 2012, and the master degrees from the Multidisciplinary Faculty of the Hassan I University, Khouribga, Morocco, in 2013, and the electrical engineer diploma in embedded systems and numerical control from the National School of Applied Sciences Khouribga, Morocco, 2015. Mr. Hassoune joined the Hassan II University of Casablanca, ENSEM, Morocco, in 2015 as a PhD candidate at the Laboratory of Energy \& Electrical Systems. He is now a teacher at the industrial systems engineering school (EIGSI), Casablanca- Morocco, since 2016. His research interests include electric vehicles charging station with several publications in highly indexed journals. He is also a member of IEEE community with access to the world's largest technical professional organization dedicated to advancing technology for the benefit of humanity.

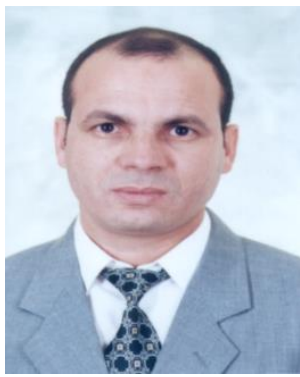

Mohamed Khafallah is now a professor tutor in the Department Electrical Engineering at the Superior National School of Electricity and Mechanical (ENSEM), Hassan II University of Casablanca, Morocco. His main research interests the application of power electronics converts and motor drives. He has published a lot of research papers in international journals, conference proceedings as well as chapters of books.

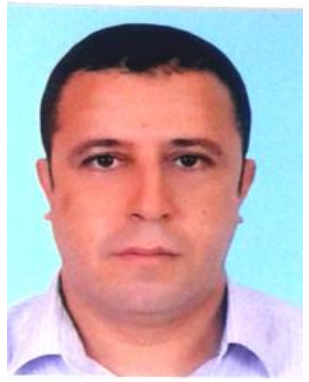

Abdelouahed Mesbahi received the M.A degree from ENSET, Rabat, Morocco in 1990 and the DEA diploma in information processing in 1997 from Hassan II University, Faculty of sciences Ben M'sik Casablanca, Morocco. He obtained the Ph.D. degree in engineering sciences from ENSEM Casablanca, Morocco in 2013. Until 2013, he was a teacher in electrical engineering department at ENSET Mohammedia Morocco. Actually, he acts as assistant professor in electrical engineering department at ENSEM, Casablanca, Morocco. His research in Energy and Electrical Systems Laboratory (LESE), is focused on sensorless control and advanced command applied to electrical machines and control of renewable energy systems. He is also an associated research member of SSDIA Laboratory based in ENSET, Mohammedia, Morocco. 


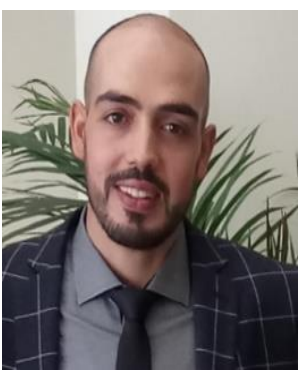

Ayoub Nouaiti was born in Morocco in 1987. He received the engineering degree in electrical engineering from the Faculty of Science and Technologies in 2011, Beni Mellal, Morocco; and the Phd degree in electrical engineering in 2019 from the National Higher School of Electricity and Mechanics (ENSEM), Hassan II University, Casablanca, Morocco. His current research interests are in the application of power electronics converters, motor drives, intelligent and digital control using the DSP implementations, renewable energy integration.

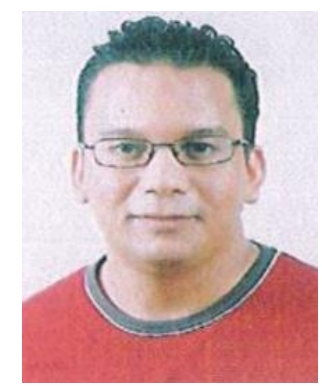

Tarik Bouragba is the Associate Professor, Department of Physics in EIGSICA engineering school o industrial system, Casablanca, Morocco. He completed his M.Sc, Ph.D degrees in Physics from Blaise Pascal University, Clermont-Ferrand, France. He worked as Replication Process Manager for 3 years at Nemotek Technologies SA, Rabat, Morocco. He had participated in many national and international workshop, seminars and conferences. He has 3 years of experience in material research and 3 years in teaching. His area of research includes material science, nanotechnology for cells application. His ongoing activities are focusing on renewable energies. 